\title{
The Impact of Macroeconomic Variables on Credit Risk (Case Study Cooperative Development Bank)
}

\author{
Mojtaba Jafari ${ }^{1}$, Mehdi Adibpour ${ }^{1} *$ \\ ${ }^{I}$ Department of Economics, FiroozkoohBranch, Islamic Azad University, Firoozkooh, Iran
}

\begin{abstract}
In this study, the connection between the macroeconomic factors and the banks credit risk has been searched. The macroeconomic factors including economic growth rate, inflation, the volume of currency, exchange rates. In order to measure the credit risks, they use the non-current facility. The search on the cooperative development bank started 2010 to 2015. In this study, the linear list squares method to estimate the model, and then check the relevant assumptions were used. The results show that there is a positive and meaningful relationship between the inflation, liquidity, exchange rates and the bank credit risk. According to the results of finding, the bank manager should have care the macroeconomic factors affecting on the credit risk, in the credit policies affairs.
\end{abstract}

Keywords: credit risks, inflation, exchange rates, positive and meaningful relationship.

\section{Introduction}

Over the past two decades, financial crisis in the banking system causes harm to many banks and credit institutions and the bankruptcy of some in the world economy. The results from such crisis shows the most important task of observers are to identify the resources crisis in order to reduce the severity and effects of crisis. The amount of maturity and deferred bank loans are from 5000 billion Tumen,(2002 ) to more than 81000 billionsTumen (2014) and the growth of deferred loans from 5 percent (2002) to 18 percent (2013) and then about 14 percent (2014) and it is the indication of the severity growth of deferred loans for 13 years and specially (2005-2013) ( about 8 years ).

Because of the increasing bank loans in the country's banking system(in the all parts from 2002) are increasing, apparently, the macroeconomic condition has an important role on the bank credits enhancements and some bank quality. The crisis in the financial system could lead to withdraw the depositor's savings. If uncertainty and unstable conditions are felt by depositors in the banking system and find better policy to maintain and keep their savings, attempting to withdraw their deposits from their banks. In addition, since the bank grants the bulk of their customer's deposits in the form of loans (facilities), if the loans are not repaid on time, then faced with a sudden reduction in resources and on pessimistic situation may even lead to bankruptcy of banks. Generally, we can say that the financial crisis refers to a shock or sudden and rapid change on all or most financial indicators such as short -term interest rates,asset prices, changes in behaviour and performance management, bankruptcy and the collapse of financial institutions. A small financial turmoil led to the financial crisis and it is dependent on factors such as:

1. The fragility of the banking credit growth

2. Reverse speed expectations

3. Lack of public confidence

4. Failure of a financial institution.

In Iran, the banks are the most important financial institutions and the credits are the lifeblood of the banking system. Also, the credit distribution for both affected by monetary macroeconomic policies in the fiscal any areas. Because most of the banks are dependent on the governmental sector in term of capital, as a result, the first attention is to provide resources by the bank. In the case of government support from governmental banks to prevent the bankruptcy, the increase of delayed loans fall to achieve the aims of providing banking facilities for the economic growth and resource loss. The greate crisis lead to create the greatereconomic depression and this is as the notable examples. So the investors according to the economic conditions and the forcast, along with having the specific purpose of the program, taking loans from their banks.In fact, investors with a long term look into the matter. Because of the time elapsed since the initial investment plan should be to step up productivity and profitability.In the meantime, maybe there policies in the financial sector caused damage to the profitability of investment conditions. Customer fails to meet its obligations to act in the banking system.So, this is the main reason for the non-payment of instalments and convert them to non-performing loans on time .In the event of facilities being deferred, and brunt finally, then the biggest losses are for the banks, because if the bank asks the customers to convert the cash collateral to monies, shall have to bear the financial and time cost, with the proviso that the initial amount of Facility will be given again. infact, the deferred loans 
are from two sections : the first section is completely Voluntary and optional from the individual borrowers and another part is the impacted of factors which are not available to the borrowers including the financial and macroeconomic conditions such as inflation, exchange rates, beneficial rates and ....

So, it is essential to pay attention and management in the field of internal and external factors that influence upon the facilitate and delayed loans.survival or profitability of institute depends on many factors which dome of them are in the control and some of them are out of the control. The banks and the financial institutions face many risks such as each other financial institute and the Technical innovations and more complex financial systems make risk management principles to be an indispensable component of any financial institution. The banking and financial system with respect to the special features face to the various kinds of risks such as: credit risks, liquidity risks and bazaar risks . (Khalil Arjomandy and Siah .2013).

On the other hand, most of countries during two last decades, face crisis and then the most of active institutions stopped their actions or have been forced to restructure .

the global banking studies show that the crisis cause to weak the country's financial sources. The crisis reveal the relation between the economic conditions and the banking system safety because in the crisis periods , the level of non- current receivables drastically increase and consequently the notable volume of banking sources decreased .( Spinza and Perasad , 2010 ). With respect to the country's monetary and financial business are axis bank and the banks possess the bulk of liquidity country. The banking system role in the economical development and growth of countries for Resource mobilization and financing for the project, funding working capital units, and meet the basic needs of the population and prevent the deepening trend of declining economic activity, investment and employment .So, one of the most important national challenges in our country system is the increasingly manner of delayed receivables causes to lockout resources and decrease liquidity. (Borhany, 2010).

The cooperative development bank is Most specialized monetary and financial banking institution is obliged to use the facilities of the cooperative sector in order to enhance the capacity and capabilities with the objective of increasing the share of cooperative sector in national economy and helping to the social and economical development via the development of cooperative sector and supplying a suitable context for cooperative development in the economical activities. So, the risk management is very important specially upon the relationship between the macroeconomic and the banking credit risk.Mantez (2014) search for the influence of the macroeconomic variables upon the credit risk in the commercial banks especially in the Kenya 's banking system. GDP per capita growth rates, interest rates, exchange rates between the dollar and Kenyan Shilling America, inflation, and domestic credit to the private sector by commercial banks This study started from 1990 - 2013 and for twenty-three years have elapsed and secondary data is used annually. The dependent variables are the searching for the deferred receivables and the independent macroeconomic such as :

1. The regression equations ( ols )

2. The error correction model in equation and values in the meaningful level ( $\% 5$ )

The findings show that only G.D.P per capita growth rate significantly influence upon the credit risk in the short-term.

In long-term, the role of variables were notable at the description of the credit risk. Among the macroeconomic variables, G.D.P. exchange rate, inflation and intrinsic risk causes to decrease the credits and to increase the interest's rate. And the ratio of capital to assets ratio of loans to deposits is estimated using a fixed effect model for FE. The result shows that a significant and positive relationship between the rate of economic growth, inflation, exchange rate and credit risk of banks. Mehrara and Mehranfar (2013) search for the influential factors upon the iran banking industry risk management in the period of 2001-2009 and based on the fifteen private and governmental active bank in Iran.Mehrara and Mehranfar (2013) search for the influential factors upon the Iran banking industry risk management in the period of 2001-2009 and based on the fifteen private and governmental active banks in Iran.Therefore, factors affecting the banking and economic indices are divided in to two groups divided.The results show that the regression model estimation in the theoretical data can show the Liquidity ratios, profitability and operational efficiency as well as economic growth had positive effect and the credit risk and inflation rate has a negative effect on the capital adequacy ratio as an indicator of the bank's risk management performance. Basically, the financial decisions are based on two concepts 1.Risk and 2. Efficiency.There is still disagreement about the concept of risk. The Words Ryskar risk is derived from the Italian word with the meaning to attempt to work courageously taken. Some knows the risk as a dangerous causes to Adverse deviation from what is expected to cause unsuitable future results .

\section{The Economical Growth}

The quantity change of each variable during a special period of time is called growth. in the simply definition, the economical growth is the productive increase of a country during a special year in comparison with that quantity on the basic year at the macroeconomic level. The increase of GNP or GDP in the year to ratio the quantity in a basic year is called economical growth.In the study, the growth of GDP and the basic 
years chosen based on the central bank information in 2002 .

Inflation: a circumstance which the public price level gradually and increasingly or unsuitable increase.The monetary volume:

The total currency in circulation and demand deposits.Currency: international banking operations, which includes a set of methods, practices, procedures, rules and regulations, adopted for the exchange of goods and services among countries, is named as the exchange of foreign currencies. The descriptive variables is called as the bank deposits residuals and the GDP level and the consumer's price indicator .The search questions :

The main question:

Do the macroeconomic indicators influence upon the cooperative development bank credit risk ?

The secondary questions:

1. Is there any meaningful relation between the economical growth rate and the banking credit risk ?ï

2. Is there any correlation between the inflation rate and the banking credit risk ?

3. Do the monetary volume increase causes the banking credit risk ?

4. Do the exchange rate inflations causes the banking credit risk increasing ?

Spatial Domain:the cooperative development bank

Time Domain:the cooperative development data and the economical macroeconomic since 2005-2010

Subjective Domain: credit risk

Statistical Society: a group of people or sectors which at least possess a unique and common attribute .In the statistical society, the author want to study about the variable attributes (Bazargan and others , 1997) .the statistical society is the cooperative development bank.

\section{The Sample Volume}

It is a set of signs which is choice from a sector, a group or the greater societies. Therefore, the collection is the introduction of quality and the attributes, groups or a greater society (khaki, 2003). in other definition : the restrictive quantity of statistical society shows the main attributes of society (Azar and Momeny ,2004). In the study,the samples volume are seasonal data and the cooperative development bank and nineteen subjects .

\section{The Statistical Analysis of Data}

The kind of the data is time-seasonal series. To check the time series, the Dickey-Fuller test increased, have been used. With regard to the implementation of the conditions, to meet the reliability of the time series, Angel Granger test was used.

Table 1: Estimation of regression coefficients

\section{Analysis}

Inflation was the estimated coefficient obtained for the index is $48 \%$ and with the probability of $-0 \% 48$. Given that the probability of t-statistic is less than 5\%, after significant factor is acceptable. Negative sign of the coefficient means that the impact of inflation on credit risk is negative.

The consumer's price indicators: the coefficient is $-16 \%$ with the probability $\% 107$. With respect to the statistical probability $(t>\% 5)$, then the coefficient is not meaningful and agreeable .

The G.D.P. : The coefficient is $-1 / 62 \mathrm{e}-5$ with the probability of $0 / 001$. With respect to the statistical probability $\mathrm{t}>\% 5$, this is a meaningful and agreeable coefficient .

Theeconomical growth rate : the coefficient is $6 / 34 \mathrm{e}$ and with the probability $0 / 15$. with respect to the statistical probability $\mathrm{t}>0 / 05$, then rhe coefficient is not meaningful and acceptable .(Table2)

\section{Conclusions}

The result of first hypothesis is agree with Hemmaty and Mohebynezhad ( 2007), shehry and nadery (2012) , Mehrara and Mehranfar (2013), wietro and Kastre (2013), MelsiAlisy and Monika Saloatama (2014), loinsa and Imatork (2014) and GiyongaKaroity (2014) . theresuts show that the credirisk of banks during the economical boom have been increased and during the economical downturn have been decreased .In economic conditions, both lenders and borrowers confident to investment projects and repayment ability. Banks have decreased the crackdown on the conditions for obtaining loans have and thus incur more risk. While an economic downturn, banks are conservative and provide conditions for obtaining loans more difficult. In this case, only the most qualified applicants will be able to get new loans. Then lending in recession, lead to a lower level of credit risk which is more reliable. The result of second hypothesis is agree with the Hemmaty and Moheddynezhad( 2007 ), Mehrara and Mehranfar (2013) and GitongaKaroity ( 2014 ) and is contrast with Shehry and Nadery (2012) and MelsyaliSy and Monika Salowatoma ( 2014 ). then according to this, the increasing of the inflation rate is equal to the increasing of the customer's asset values . then the customer prefer 
to Timely settle their facilities to bail them is not difficult. Then there is the meaningful relationship between liquidity and risk, then the third hypothesis is not accepted and is accordance with Nadery and shehry (2012) .

\section{Reference}

[1] ArjomandyKhalil ,Gholamreza and SanadSiah (2013), Risk management in the banking system , the first print , Dastan Publishing

[2] Shehry ,Saber and Naderi , Mohammed mehdy, the study of relationship macroeconomic factors and the banking credit risk , the accounting searches, no 21, winter2012

[3] Gaskary ,Reyhaneh,Ghanbary, Hasanali and Eghbali, Alireza, non-stable in the macroeconomic and investment in the special sector in iran, economical searches, 2006.

[4] MehrAra, Mohsen and Mehranfar, Mahdy, Alamrradybadanry and the macroeconomic factors in the risk management, economical modelling, the seventh year, no. 2 ,spring2013.

Table 1: Estimation of coefficients in model

\begin{tabular}{|l|l|l|l|}
\hline Variable & Coefficient & Standard deviation & Probability \\
\hline C & 11.14022 & 2.127876 & 0.0004 \\
\hline D(CPI) & -0.048484 & 0.021596 & 0.0486 \\
\hline CPI & -0.016124 & 0.009129 & 0.1078 \\
\hline GDP & $-1.62 \mathrm{E}-05$ & $3.67 \mathrm{E}-06$ & 0.00113 \\
\hline D(LGDP) & $4.34 \mathrm{E}-06$ & $2.78 \mathrm{e}-06$ & 0.1502 \\
\hline LIQ & $-5.31 \mathrm{E}-07$ & $2.86 \mathrm{E}-07$ & 0.0930 \\
\hline EXR & $5.40 \mathrm{E}-05$ & $2.50 \mathrm{E}-05$ & 0.0560 \\
\hline DEP & 0.176379 & 0.037790 & 0.0009 \\
\hline
\end{tabular}

Table 2: significance of estimated coefficients

\begin{tabular}{|l|l|l|}
\hline Kind of relation ship & Explanatory variable & variable \\
\hline Negative and significant relationship & Inflation & \\
\cline { 1 - 2 } $\begin{array}{l}\text { Negative and non-significant } \\
\text { relationship }\end{array}$ & CPI & \\
\hline Negative and significant relationship & GDP & \\
\hline Positive and non-significant relationship & Economical growth & \\
\hline Negative and significant relationship & Liquidity & Internal factor \\
\hline Positive and significant relationship & Exchange rate & \\
\hline Positive and significant relationship & Sum of bank deposit & \\
\hline
\end{tabular}

